\title{
Effect of designed nursing guidelines on acute anal fissure treatment outcomes
}

\author{
Esmat Sayed Abd-Elmaged*1, Amna Abdallh Desoky ${ }^{1}$, Tarik Abd-Elazem Abd-Elrahem²,3 \\ ${ }^{1}$ Faculty of Nursing, Assiut University, Assiut, Egypt \\ ${ }^{2}$ Faculty of Medicine, Assiut University, Assiut, Egypt \\ ${ }^{3}$ Faculty of Medicine, Helwan University, Cairo, Egypt
}

Received: February 12, 2018

DOI: $10.5430 /$ jnep.v8n10p1
Accepted: April 19, $2018 \quad$ Online Published: May 7, 2018

URL: https://doi.org/10.5430/jnep.v8n10p1

\begin{abstract}
Objective: Anal fissure is a common problem through the world, it causes considerable morbidity. The aim of the study was to evaluate the effect of designed nursing guidelines on acute anal fissure treatment outcomes.

Methods: Research design: Quasi-experimental design. Setting: General Surgery Wards and Outpatient Clinics of General Surgery at Assiut University Hospital. Sample: A purposive sample of 60 male and female adult patients diagnosed of having acute anal fissure. Patients were equally divided on random basis into two equal groups (study and control) 30 patients for each. Tools: Tool I-Patient assessment sheet. Tool II-Numeric Pain Rating Scale. Tool III-Bates-Jensen Wound Assessment Tool.

Results: No statistically significant difference was found between the study and the control groups as regard demographic data. There was a statistically significant improvement in the pain level and wound healing among the study group (1.63 \pm 2.08 and $11.93 \pm 4.5$ respectively) than in the control group ( $2.87 \pm 2.33$ and $14.43 \pm 4.29$ respectively). Also, there was a high statistically significant improvement in the level of knowledge of the study group than their level before applying the guidelines $(p<.001)$.

Conclusions: Designed nursing guidelines had a statistically significant effect on improving patients' knowledge, pain level, and wound healing among the study group patients than among the control group ones with acute anal fissure. Recommendations: Patients teaching should be an integral part of the nurses' duty in all hospitals. Further studies on larger sample from different geographical areas in Egypt to generalize the results.
\end{abstract}

Key Words: Acute anal fissure, Nursing guidelines, Treatment outcomes

\section{INTRODUCTION}

Anal fissure is a tear in the lining of the anus; it is a common problem through the world; it is one of the most common painful and benign conditions of the anal region, which lead to morbidity and decrease in quality of life. Once a fissure develops, the internal anal sphincter goes into spasm, causing further separation of the tear, constricting blood flow to the fissure area, and impairing healing. ${ }^{[1,2]}$
Anal fissures are characterized by rectal pain upon defecation which is severe and can last several minutes to hours; it may cause people to avoid having a bowel movement leading to chronic constipation. Also, patients may complain from bleeding, and anal sphincter spasms. Fissures result from passage of hard stool, childbirth, explosive diarrhea, foreign body insertion, anal intercourse, or Crohn disease. Fissures can be classified into acute if it has been present for less than

*Correspondence: Esmat Sayed Abd-Elmaged; Email: dr_es_sa@yahoo.com; Address: Faculty of nursing, Assiut University, Assiut, Egypt. 
six weeks and chronic if it has been present for greater than six weeks. ${ }^{[3]}$

In acute fissures, medical management is successful in the majority of patients. The goal of management is to break the cycle of anal spasm which improves blood flow to the fissured area so that healing can occur. Healing could be achieved with conservative therapies like warm water sitz baths, analgesics, stool softeners, and dietary modifications. Also, nitroglycerin (GTN) ointment help to break the cycle of spasm, it is applied twice daily for 6-8 weeks. Headaches and lightheadedness are a very common side effect of GTN ointment. However, small proportions of acute fissures do not heal and become chronic fissures, so patients will need to surgical management. ${ }^{[4,5]}$

Patient education and health promotion are important functions of the nurse. After the medical history is obtained, the nurse sets specific goals for teaching include; restoring or maintaining a regular pattern of defecation, learning about methods to avoid constipation, relieving anxiety about bowel elimination patterns, and avoiding complications. ${ }^{[6]}$

Nurses have an important role in supporting spontaneous healing of acute anal fissure. Nursing instructions should emphasize on increasing water intake to 2 litres per day unless contraindicated. Providing a list of high-fiber diet. Teaching the patient to heed the urge to defecate. Cleansing of the perianal area with water and to dry with cotton rubs to avoid infection and irritation. Teaching patient how to do sitz baths using warm water daily. Following diet and medication instruction, to promote compliance with the treatment regimen and to prevent complications. Encouraging exercise to enhance wound healing and maintain normal stool patterns. ${ }^{[7]}$

\subsection{Significance of the study}

According to Assiut University Hospital records (2016), the anal fissures patients flow rate in Outpatient Clinics of General Surgery was about 480 cases. But the incidence of anal fissure in Egypt was not accessible. Also, from the researchers' experiences, it was noted that patients' knowledge about acute anal fissure are inadequate and need for improvement. Therefore this study is considered the first one in this geographical location to help patients increasing their knowledge about acute anal fissure which may reduce their complaining and improve healing of acute anal fissure.

\subsection{Aim of the study}

The aim of this study was to evaluate the effect of designed nursing guidelines on acute anal fissure treatment outcomes.

\subsection{Research hypotheses}

To fulfil the aim of the study, the following research hypotheses were formulated:

(1) After applying the designed nursing guidelines, the study group patients will show higher mean knowledge scores than before applying the designed nursing guidelines.

(2) Mean pain scores after applying the designed nursing guidelines will be lesser in the study group than in the control group.

(3) Healing of the acute anal fissure after applying the designed nursing guidelines will be improved among the study group than among the control group.

\subsection{Operational definitions}

Treatment outcomes: It included patients' knowledge, pain level, and anal fissure healing.

\section{Patients And method}

\subsection{Research design}

Quasi-experimental design was utilized in this study.

\subsection{Study variables}

The independent variable was the designed nursing guidelines, while the dependent variables were patients' knowledge, pain as well as healing of the anal fissure.

\subsection{Setting}

The study was conducted in the General Surgery wards and Outpatient Clinics of General Surgery at Assiut University Hospital - Egypt.

\subsection{Sample}

A purposive sample of 60 male and female adult patients diagnosed of having acute anal fissure, their age ranged from 18 to 65 years. Patients were equally divided on random basis into two equal groups (study and control) 30 patients for each. The study group received the designed nursing guidelines while the control group received the routine care.

\subsection{Exclusion criteria}

- Chronic anal fissure.

- Previous surgical treatment for anal fissure.

- Rectal or anal malignancy.

- Other anorectal diseases (e.g., hemorrhoids, fistulae, and anal abscesses). 


\subsection{Tools of the study}

Tool I-Patient assessment sheet: It was developed and used by the researcher after literature review and consisted of two parts:

Part 1-Demographic data of the studied groups: Age, sex, marital status, educational level, occupation, and residence.

Part 2-Patients' knowledge about anal fissure: Definition, types, causes, signs and symptoms, complications, and management. Patient assessment sheet was administered by the researchers to the patients for answering all its content, with help for patients with reading problems.

Scoring system: The total number of questions was 7 list questions and the total score was 30 . One score was given for each right answer and zero for wrong answer. Patients who obtained less than $50 \%$ were considered having unsatisfactory level of knowledge, while those who obtained more than $50 \%$ were considered having satisfactory level of knowledge.

Tool II-Numeric pain rating scale: It is one of the most common assessment tools for quantifying pain intensity. It is commonly used when assessing adults through providing a verbal response, which the healthcare provider can then document. This does not require the patient to write or use a ruler and is also useful for telephone assessments. ${ }^{[8]}$ It was adopted in this study by the researchers for monitoring pain of the anal fissure.

Scoring system: Numeric pain rating scale is ranged from 0 to 10. It indicates the intensity of pain levels through asking the patients to rate their pain from 0 to 10 with the understanding that 0 is equal to no pain and 10 is equal to worst possible pain.

Tool III-Bates-Jensen Wound Assessment Tool (BWAT): It was developed by Bates-Jensen in 2001, it is used to assess and monitor healing of all types of wounds. It contains 13 items that describe the characteristics of the wound for purposes of categorization and treatment. ${ }^{[9]}$ It was adopted in this study by the researchers for monitoring healing of the anal fissure. The 13 items of the BWAT included:

(1) Size: Use ruler to measure the longest and widest aspect of the wound surface in centimeters; multiply length $\mathrm{x}$ width. Score as $=0$ if wound healed.

(2) Depth: Pick the depth and thickness, score as $=0$ if wound healed.

(3) Edges: Diffuse, attached, not attached, rolled under thickened, or hyperkeratosis scarred. Score as $=0$ if wound healed.

(4) Undermining: Insert cotton tipped applicator under the wound edge; raise the tip of the applicator to see on the skin surface; mark the surface with a pen; measure the distance from the mark to the wound edge. Score as $=0$ if wound healed.

(5) Necrotic tissue type: Pick the type of necrotic tissue that is predominant in the wound according to color, consistency and adherence.

(6) Necrotic tissue amount: It is divided into 4 (25\%) pieshaped quadrants to help determine percent of wound involved.

(7) Exudate type: Bloody, serosanguineous, serous, purulent, or foul purulent.

(8) Exudate amount: None, scant, small, moderate, or large.

(9) Skin color surrounding wound: Assess tissues within $4 \mathrm{~cm}$ of wound edge. As healing occurs in dark-skinned persons, the new skin is pink and may never darken.

(10) Peripheral tissue edema: Firmly pressing a finger down into the tissues and waiting for 5 seconds, on release of pressure tissues fail to resume previous position.

(11) Peripheral tissue induration: Is abnormal firmness of tissues with margins. Assess by pinching the tissues. Induration results in an inability to pinch the tissues.

(12) Granulation tissue: Is the growth of small blood vessels and connective tissue to fill in full thickness wounds. Tissue is healthy when bright, red, shiny and granular with a velvety appearance.

(13) Epithelialization: Is the process of epidermal resurfacing. It is divided into $4(25 \%)$ pie-shaped quadrants to measure the distance the epithelial tissue extends into the wound.

Scoring system: It is a five-point Likert scale, where 1 indicates the best condition of the wound and 5 indicates the worst condition. The total score was obtained from the summation of all the items, and can range from 13 to 65 points, with higher scores indicating the worst wound conditions. Below 13 = healed, 13-20 = minimal severity, 21-30 = mild severity, $31-40=$ moderate severity, and $41-65=$ extreme severity.

\subsection{Ethical consideration}

Permission to carry out the study was obtained from the ethical committee of the faculty of nursing and from the hospital authorities of General Surgery wards and Outpatient Clinics of General Surgery at Assiut University Hospital. Prior to the initial interview, the researchers introduced themselves to patients. Oral agreement for voluntary participation was obtained. Anonymity and confidentiality were assured through coding of the data. The patients had the right to refuse to participate in the study and can withdraw at any time. 


\subsection{Content validity}

It was established by a panel of seven experts (included 4 experts from Medical Surgical Nursing staff and three from the General Surgery staff) who reviewed the tools for clarity, relevance, comprehensiveness, understanding, and applicability. Minor modifications were required. Test reliability of the proposed tools was ascertained with Cronbach's alpha = 0.88 .

\subsection{Pilot study}

It was implemented on $10 \%$ of the sample, to ensure clarity of the tools, examine utility of the tools, and identify any difficulties needed to be handled. No changes were done to the tools, so the sample of the pilot study was included in the actual study sample.

\subsection{Treatment protocol}

The treatment protocol for the study group patients was similar to the control group, it involved topical glyceryl trinitate (GTN) ointment 2 times a day, stool softener, and topical anesthetic creams. However the study group applied the designed nursing guidelines. This treatment protocol was continued for 6 weeks.

\subsection{Designed nursing guidelines}

The guidelines were developed by the researchers through reviewing of related literature and research results regarding managing of anal fissure. The guidelines involved knowledge about anal fissure (definition, types, causes, signs and symptoms, diagnosis, complications, and treatment) and nursing instructions to be followed (high fiber diet, plenty of oral fluid, warm water sitz bath 2 times a day, cutting nails to avoid injury to the anal area either during applying the ointment or from itching, good hygiene to the anal area without using any irritant materials, keeping the area dry to avoid irritation, exercises to enhance intestinal movement and to increase blood flow which help in the healing process, the proper method for applying the ointments for the anal region where the patient should use a disposable glove to cover his or her finger, then putting the ointment from the tube on the finger, then gently inserting the ointment to about $0.5 \mathrm{~cm}$ inside the anus). Experts in fields of nursing and surgery checked the content for comprehensiveness, clarity, relevancy and applicability and corrections were carried out accordingly.

\subsection{Procedure}

The study proceeded using the following phases:

Assessment phase: The researchers met the selected patients; each patient from both groups (study and control) was fully informed with the purpose and nature of the study and the patients' agreement was obtained. Base line data were established using tool I, tool II, and tool III.

\section{Implementation phase:}

- The study group was given the designed nursing guidelines by the researchers; each patient was met for one session. Each session took about 30-40 min. The study was carried out in the morning and afternoon shifts.

- Guidelines were given on an individual basis. One of the family members was present in the session to ensure patient support.

- During the session each patient was given handouts 'booklet' after extensive literature review and included photographs and guidance related to the disease in clear Arabic language, to help them retain the learned material.

- A brief review was elicited from the patients to assess his or her understanding, then the researchers clarified any points that the patient did not understand.

- The designed nursing guidelines were carried out throughout a period of 6 weeks for the study group only while the control group received the routine care.

- The researcher arranged with the patients in both groups (study and control) the time and place for follow up which were after 6weeks in the Outpatient Clinics of General Surgery at Assiut university hospital.

- The researchers ensured commitment of the study group patients to implement the nursing guidelines weekly by telephone.

- Data were collected through the period from the beginning of January 2017 to the end of August 2017.

Evaluation phase: In this phase, patients were reassessed at the 6th week after the first assessment using tool I part 2, tool II, and tool III. Both study and control group patients attended the follow-up sessions in the Outpatient Clinics of General Surgery to evaluate the effectiveness of the designed nursing guidelines. The session took approximately 20 minutes.

\subsection{Statistical analysis}

Data obtained and analyzed through using computer program SPSS version 22 (Statistical Package for Social Science). Results were presented as number, percentage, mean and standard deviation. Chi-square test and Fisher Exact test were used to compare between qualitative variables. MannWhitney test was used to compare quantitative variables. Wilcoxon Signed Ranks Test was used to compare quantitative variables between pre-test and post-test in case of non-parametric data. $p$-value considered statistically significant when $p<.05$. 


\section{RESULTS}

Table 1 shows that the mean age of study and control groups

patients was $35.67 \pm 14.10$ and $34.70 \pm 14.05$ respectively, Figure 1 clarifies that the highest percentage among the and the highest percentage of them was female, married, causes of acute anal fissure in both study and control groups and from rural area (73.3\% and 63.3\%), (70.0\% and 83.3\%), was constipation (66.7\% and 50\%), childbirth (26.7\% and $(56.7 \%$ and $70 \%)$ respectively. No statistically significant $40.0 \%)$, and diarrhea (6.7\% and $10 \%)$ respectively.

Table 1. Frequency distribution of demographic characteristics of the studied sample (study \& control groups)

\begin{tabular}{|c|c|c|c|c|c|}
\hline \multirow{2}{*}{ Characteristics } & \multicolumn{2}{|c|}{ Study $(n=30)$} & \multicolumn{2}{|c|}{ Control $(n=30)$} & \multirow{2}{*}{$p$-value } \\
\hline & No. & $\%$ & No. & $\%$ & \\
\hline \multicolumn{6}{|l|}{ Age } \\
\hline $18<35$ years & 13 & 43.3 & 16 & 53.3 & \\
\hline $35<50$ years & 11 & 36.7 & 5 & 16.7 & $.796^{\mathrm{NS}}$ \\
\hline 50-65 years & 6 & 20.0 & 9 & 30.0 & \\
\hline Mean \pm SD & \multicolumn{2}{|c|}{$35.67 \pm 14.10$} & \multicolumn{2}{|c|}{$34.70 \pm 14.05$} & \\
\hline \multicolumn{6}{|l|}{ Sex } \\
\hline Male & 8 & 26.7 & 11 & 36.7 & $.405^{\mathrm{NS}}$ \\
\hline Female & 22 & 73.3 & 19 & 63.3 & \\
\hline \multicolumn{6}{|l|}{ Occupation } \\
\hline Employee & 8 & 26.7 & 9 & 30.0 & $.774^{\mathrm{NS}}$ \\
\hline Farmer & 4 & 13.3 & 5 & 16.7 & $.718^{\mathrm{NS}}$ \\
\hline Housewife & 10 & 33.3 & 9 & 30.0 & $.781^{\mathrm{NS}}$ \\
\hline Student & 5 & 16.7 & 2 & 6.7 & $.424^{\mathrm{NS}}$ \\
\hline Skilled worker & 3 & 10.0 & 5 & 16.7 & $.706^{\mathrm{NS}}$ \\
\hline \multicolumn{6}{|l|}{ Marital status } \\
\hline Single & 9 & 30.0 & 5 & 16.7 & $.222^{\mathrm{NS}}$ \\
\hline Married & 21 & 70.0 & 25 & 83.3 & \\
\hline \multicolumn{6}{|l|}{ Level of education } \\
\hline Illiterate & 2 & 6.7 & 8 & 26.7 & \\
\hline Basic education & 8 & 26.7 & 3 & 10.0 & $.115^{\mathrm{NS}}$ \\
\hline Secondary & 10 & 33.3 & 10 & 33.3 & \\
\hline University & 10 & 33.3 & 9 & 30.0 & \\
\hline \multicolumn{6}{|l|}{ Residence } \\
\hline Urban & 13 & 43.3 & 9 & 30.0 & $.284^{\mathrm{NS}}$ \\
\hline Rural & 17 & 56.7 & 21 & 70.0 & \\
\hline
\end{tabular}

Table 2 reflects that the mean knowledge scores of both study and control groups were low $(5.43 \pm 3.35$ and $6.13 \pm 3.45$ respectively) in pre-test. However, in the time of follow up "6 weeks after nursing guidelines application" there was a statistically significant improvement in the level of knowledge of the study group $(23.33 \pm 3.50)$ than their level before applying the guidelines $(p<.001)$.

Table 3 demonstrates that at the beginning of the study all patients in both groups (study \& control) suffered from fissure pain as a base line data with a mean score $(8.87 \pm 1.11$ and $8.73 \pm 0.74$ respectively), no significant statistical difference in the mean pain score between both groups. However, there was an obvious significant improvement in the pain level Published by Sciedu Press difference was found between both groups regarding the demographic data. 


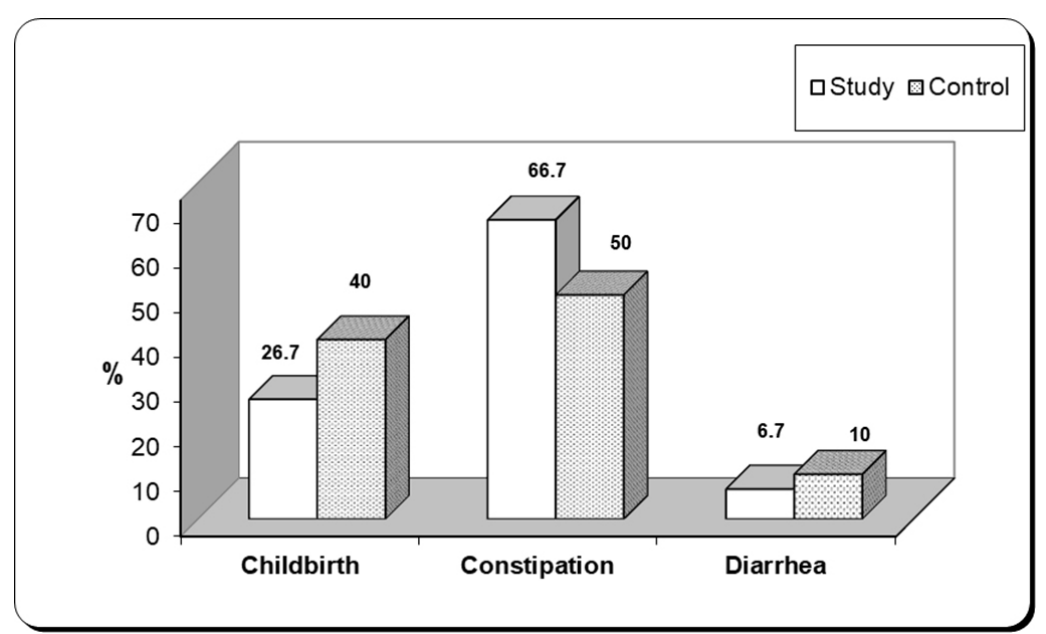

Figure 1. Frequency distribution of causes of acute anal fissure among study \& control groups

Table 2. The mean knowledge scores of both groups (study \& control) about anal fissure

\begin{tabular}{|c|c|c|c|c|c|}
\hline \multirow{3}{*}{ Knowledge score } & \multicolumn{2}{|l|}{ Study } & \multirow{2}{*}{$\begin{array}{l}\text { Control } \\
\text { Pre-test }\end{array}$} & \multirow{3}{*}{$p_{1}$} & \multirow{3}{*}{$p_{2}$} \\
\hline & Pre-test & Post-test & & & \\
\hline & Mean \pm SD & Mean \pm SD & Mean \pm SD & & \\
\hline Mean \pm SD & $5.43 \pm 3.35$ & $23.33 \pm 3.50$ & $6.13 \pm 3.45$ & \multirow{2}{*}{$.0001^{* * *}$} & \multirow{2}{*}{$.462^{\mathrm{NS}}$} \\
\hline Range & $1.0-14.0$ & $16.0-30.0$ & $1.0-13.0$ & & \\
\hline
\end{tabular}

Note. NS: Not Significant $p>.05 ;{ }^{* * *}$ Highly Significant $p<.001$.

Table 3. Comparison of pain scores as a main complaint among study \& control groups

\begin{tabular}{llll}
\hline Pain score & Study $(\mathbf{n}=\mathbf{3 0})$ & Control $(\mathbf{n}=\mathbf{3 0})$ & $\boldsymbol{p}_{\mathbf{1}}$ \\
\hline Pre-test & & & $.293^{\mathrm{NS}}$ \\
Mean \pm SD & $8.87 \pm 1.11$ & $8.73 \pm 0.74$ & \\
Range & $7-10$ & $7-10$ & $.017^{*}$ \\
Post-test & & & \\
Mean \pm SD & $1.63 \pm 2.08$ & $2.87 \pm 2.33$ & \\
Range & $0-8$ & $0-8$ & $.001^{* *}$ \\
$\boldsymbol{p}_{2}$ & $.001^{* *}$ & & \\
\hline
\end{tabular}

Note. NS: Not Significant $p>.05 ;{ }^{*}$ Significant $p<.05 ;{ }^{* *}$ Significant $p<.01$.

Table 4. Distribution of anal fissure healing outcomes according to Bates-Jensen Wound Assessment Tool scores at baseline and at 6 weeks follow-up interval

\begin{tabular}{|c|c|c|c|c|c|}
\hline \multirow{2}{*}{ Wound level } & \multicolumn{2}{|c|}{ Study $(n=30)$} & \multicolumn{2}{|c|}{ Control $(n=30)$} & \multirow[t]{2}{*}{$p_{1}$} \\
\hline & No. & $\%$ & No. & $\%$ & \\
\hline \multicolumn{6}{|l|}{ Pre-test } \\
\hline Completely healed & 0 & 0.0 & 0 & 0.0 & \multirow{3}{*}{$1.000^{\mathrm{NS}}$} \\
\hline Minimal severity & 3 & 10.0 & 3 & 10.0 & \\
\hline Mild severity & 27 & 90.0 & 27 & 90.0 & \\
\hline \multicolumn{6}{|l|}{ Post-test } \\
\hline Completely healed & 21 & 70.0 & 12 & 40.0 & \multirow{3}{*}{$.027^{*}$} \\
\hline Minimal severity & 6 & 20.0 & 16 & 53.3 & \\
\hline Mild severity & 3 & 10.0 & 2 & 6.7 & \\
\hline$p_{2}$ & \multicolumn{2}{|c|}{$.001^{* *}$} & \multicolumn{2}{|c|}{$.0001^{* * *}$} & \\
\hline
\end{tabular}


Table 5 demonstrates that the mean PWAT scores after 6 weeks of treatment in both study and control groups was $11.93 \pm 4.53$ and $14.43 \pm 4.29$ respectively, which was significantly lower (improved) than pre-test $(24.13 \pm 2.83$ and
$23.40 \pm 2.66$ respectively). Overall, there was a statistically significant improvement in the wound healing among the study group patients in comparison with the control group ones in the same period of time $(p<.01)$.

Table 5. The mean score of Bates-Jensen Wound Assessment Tool among study \& control groups at baseline and at 6 weeks follow-up interval

\begin{tabular}{lccc}
\hline Wound score & Study $(\mathbf{n}=\mathbf{3 0})$ & Control $(\mathbf{n}=\mathbf{3 0})$ & $\boldsymbol{p}_{\mathbf{1}}$ \\
\hline Pre-test & & & $.317^{\mathrm{NS}}$ \\
Mean \pm SD & $24.13 \pm 2.83$ & $23.40 \pm 2.66$ & $.004^{* *}$ \\
Post-test & & & $14.43 \pm 4.29$ \\
Mean \pm SD & $11.93 \pm 4.53$ & $.001^{* *}$ & \\
$\boldsymbol{p}_{\mathbf{2}}$ & $.001^{* *}$ &
\end{tabular}

Figure 2 illustrates that regarding the study group, $70 \%$ of the patients their fissures completely healed, $20 \%$ their fissures remained unchanged and only $10 \%$ had undergone surgery.
According to the control group, $40 \%$ of the patients their fissures completely healed, $46.7 \%$ their fissures remained unchanged, and $13.3 \%$ had undergone surgery.

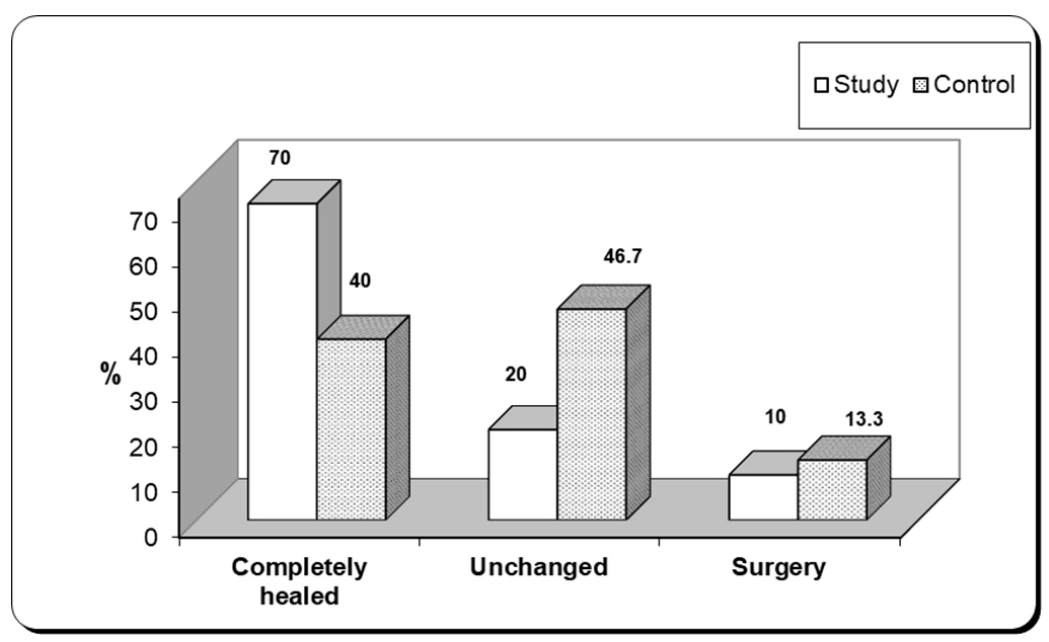

Figure 2. Frequency distribution of progress of acute anal fissure among study \& control groups

\section{Discussion}

Anal fissure is a common troublesome disease. In acute anal fissure the severity of pain and extent of disability far exceed those would be anticipated from a seemingly small lesion. While it is not a fatal condition, it can significantly affect the quality of life of the person as a result of its troubling symptoms. ${ }^{[10]}$

Regarding demographic data the present study presented that the largest percentage of both study and control groups was below 35 years of age, this can be attributed to increasing the tonicity of the muscles during this age, which resists the passage of hard stool and will result in fissure formation. This result agreed with Raj and Kadam (2014) ${ }^{[11]}$ who conducted a study on different modalities in management of fissure in ano, they found that the highest percentage of acute and chronic anal fissure cases occurs in the age group (21-30 years of age).

Mapel et al. (2014) ${ }^{[12]}$ studied 1243 patients with anal fissure and reported that women had a higher overall incidence of anal fissure than men. On the contrary among 100 patients with anal fissure Kuiri et al. (2014) ${ }^{[13]}$ found the highest rate of anal fissure was among male. While Jonas and Scholefield (2001) ${ }^{[14]}$ reported that anal fissure is equally affecting both sexes. In the current study there was a higher female predominance than male.

Related to the causes of acute anal fissure this study showed that the highest percentage in both groups was due to con- 
stipation, this result from the researcher opinion was due to lake of patients' knowledge about healthy eating habits as increasing fiber and fluid intake which lead to the passage of a hard stool and injury of the anal mucosa. Childbirth came the second cause, while the lowest percentage was due to diarrhea.

Babu et al. (2017) ${ }^{[15]}$ were in the same line with the current study, they found that the majority of patients with acute anal fissure had a history of constipation, which confirmed an association between constipation and anal fissure in their study about the effect of conservative management of acute fissure in ano. In contrary with the current study Lund and Scholefield (1996) ${ }^{[16]}$ investigated the etiology and treatment of anal fissure, the results showed that only a quarter of patients with anal fissure suffered from constipation.

Congruent with the current study Abramowitz et al. $(2002)^{[17]}$ in a prospective study of 165 women in the last three months of pregnancy and the first 10 weeks postpartum, only two women had anal fissure before delivery, but 25 women had anal fissure afterwards. Also, Sagap and Remzi (2006) ${ }^{[18]}$ added that a less commonly cause of anal fissure is prolonged-repeated diarrhea in their study about controversies in the treatment of common anal problems.

As regarding pain as a main complaint for patients with anal fissure, the current study demonstrated that at the beginning of study all patients in both groups (study \& control) suffered from severe fissure pain during defecation and can persist for a certain amount of time. This pain may be due to richness of the anal region with pain fiber that makes it a very sensitive area.

In this regard Cross et al. (2008) ${ }^{[19]}$ stated that the pain of anal fissure is so severe as to induce the patient to avoid defecation with consequent hardening of the stool and exacerbation of the anal problem. Also, Raj and Kadam (2014) ${ }^{[11]}$ concluded that pain is the chief presenting complaint in most patients with acute anal fissure.

Regarding patients' knowledge the present study revealed that all patients in both groups (study \& control) did not have enough knowledge about anal fissure before applying the nursing guidelines; this might be related to the lack of nurses' knowledge about anal fissure. However; there was a high statistically significant improvement in the level of knowledge among the study group after applying the nursing guidelines.

In the same line with the current study Khan et al. $(2015)^{[20]}$ concluded that anal fissure is a common anorectal condition. Constipation and other life style factors are the modifiable risk factors for the anal fissure. They added that health ed- ucation should be provided to the patients to adopt certain lifestyle changes that can be beneficial to limit the progress of the disease.

Regarding the effect of the designed nursing guidelines on anal fissure pain and wound healing the present study proved that after applying the nursing guidelines there was a significant improvement in the pain level and wound healing among the study group than in the control group. From the researchers point of view this may be due to containment of the nursing guidelines with the all needed instructions that help in healing of the fissure (e.g., increasing fluids and fibers, sitz bath, hygienic care, proper method for applying ointments, and exercises) plus the treatment protocol (GTN ointment, stool softener, and anesthetic creams). Also, continuous follow-up of study group by the researchers to ensure commitment of the patients to implement the nursing guidelines.

Similarly, Feldman et al. (2015) ${ }^{[21]}$ stated that our emphasis was on exercise, because lack of exercise and sedentary lifestyle are predisposing factors to the development of anal fissure. Engaging in moderate physical activity, such as walking promotes regular bowel movements which limit the onset of large hard stools, increases blood flow to all parts of the body, and may promote healing of anal fissure.

Congruent with the present study Hany et al. (2017) ${ }^{[22]}$ after six weeks of conservative treatment which include sitz baths, bulking agents, and topical GTN they reported significant improved wound healing and relieve of pain and other symptoms of acute anal fissure more than in chronic anal fissure. Similarly, Gupta (2006) ${ }^{[23]}$ concluded that patients with acute anal fissures who received sitz baths reported a higher satisfaction score than those who did not receive sitz bath and added that patients should be given specific instructions on how to carry out sitz baths correctly.

In a randomized controlled trial, Jensen (1986) ${ }^{[24]}$ found that treatment of acute anal fissuren with $10 \mathrm{~g}$ of unprocessed bran fiber twice daily and warm sitz baths for 15 minutes twice daily and after each bowel movement resulted in quicker symptomatic relief and better healing at 3 weeks period compared with $2 \%$ lignocaine ointment or $2 \%$ hydrocortisone cream. Renzi et al. (2013) ${ }^{[25]}$ added that treatment of acute anal fissure with fiber supplement has been associated with increased healing rates, improved of symptoms, and prevented the recurrence

Also, Gogna et al. (2015) ${ }^{[26]}$ supported the current study, they conducted a prospective study to evaluate the effect of sitz bath Vs lignocaine ointment Vs topical glyceryl trinitrate in treatment of acute anal fissure, the results of their study 
were proved that the effect of sitz bath is equal to GTN in the treatment of acute anal fissure, however lignocaine ointment has a lower effect. Gupta (2004) ${ }^{[27]}$ added that acute anal fissure can heal spontaneously or with simple measures like high fiber, increasing water intake, and warm sitz baths.

In this regard Babu et al. (2017) ${ }^{[15]}$ reported that during follow up of acute anal fissure after 6 weeks of giving conservative management like stool softeners and local anesthetic creams with diet modification, most of patients achieved wound healing and reduction of the mean pain score. They concluded that acute anal fissure can be easily cured with the usage of conservative treatment and added, a proper follow up with patient education can help to achieve good remission and avoid unnecessary surgical management.

\section{Conclusion}

Designed nursing guidelines had a statistically significant effect on improving patients' knowledge, pain level, and wound healing among the study group patients than among the control group ones with acute anal fissure.

\section{Recommendations}

(1) Patients teaching should be an integral part of the nurses' duty in all hospitals.

(2) Simple illustrated guidelines about acute anal fissure should be available in General Surgical wards and Outpatient Clinics of General Surgery.

(3) Further studies on larger sample from different geographical areas in Egypt to generalize the results, detect the main aspects of the problem, and gather in depth information about acute anal fissure.

\section{CONFLICTS OF INTEREST Disclosure}

The authors declare that there is no conflict of interest.

\section{REFERENCES}

[1] Rahmani NM, Khademloo K, Vosoughi S. Effects of Aloe vera Cream on Chronic Anal Fissure Pain, Wound Healing and Hemorrhaging Upon Defection: A Prospective Double Blind Clinical Trial. European Review for Medical and Pharmacological Sciences. 2014; 18: 1078-1084. PMid:24763890

[2] Fox A, Tietze PH, Ramakrishnan K. Anorectal conditions: anal fissure and anorectal fistula. FP Essent. 2014; 419: 20-27. PMid:24742084

[3] Beaty JS, Shashidharan M. Anal Fissure. Clin Colon Rectal Surg. 2016; 29(1): 718-721.

[4] Wald A, Bharucha A, Cosman B, et al. ACG Clinical Guideline: Management of Benign Anorectal Disorders. Am J Gastroenterol. 2014; 109: 1141-57. PMid:25022811 https://doi.org/10.103 $8 /$ ajg.2014.190

[5] Mandal G. A Textbook of Adult Health Nursing. 2nd ed. Dilllibazar kathmandu: Makalu publication house. 2013.

[6] Smeltzer SC, Bare BG. Brunner and Suddarth's textbook of MedicalSurgical Nursing: Digestive and Gastrointestinal Function. Lippincott, Williams \& Wilkins. 2004. 1030 p.

[7] Timby BK, Smith NE. Introductory Medical-Surgical Nursing: Caring for Clients with Disorders of the Lower Gastrointestinal Tract. 10th Edition. Wolters Kluwer Health Lippincott Williams \& Wilkins. 2010. 698-699 p.

[8] McCaffery M, Beebe A. Pain: Clinical Manual for Nursing Practice. Mosby St. Louis, MO. 1989.

[9] Bates-Jensen B, Sussman C. Tools to measure wound healing. In Sussman C, Bates-Jensen B, editors. Wound Care, a Collaborative Practice Manual for Health Professionals, 4 ed. Baltimore (US): Lippincott Williams and Wilkins; 2012. 131-72 p.

[10] Michael E, Friscia MD, Robert D. Anal pain: Office Diagnosis and Treatment. 2008; 48: 1-3.

[11] Raj VK, Kadam MM. A study on Different Modalities in Management of Fissure in Ano. Int J Sci Res. 2014; 3(10): 942-8.

Published by Sciedu Press

[12] Mapel DW, Schum M, Worley AV. The Epidemiology and Treatment of Anal Fissures in a Population-Based Cohort. BioMed Central Gastroenterology. 2014; 114: 129.

[13] Kuiri SS, Saha AK, Mandal N, et al. Comparative Study of lateral Sphincterotomy Versus Local 2\% Diltiazem Ointment for the Treatment of Chronic Anal Fissure. IOSR-JDMS. 2014; 13(6): 36-40. https://doi.org/10.9790/0853-13643640

[14] Jonas M, Scholefield JH. Surgical Treatment: Evidence-Based and Problem-Oriented. Munich: Zuckschwerdt. 2001.

[15] Babu S, Gupta R, Singh L. Effectiveness of Conservative Management of Acute Fissure in Ano: A Prospective Clinical Study of 165 patients. Int Surg J. 2017; 4(9): 3028-3033. https ://doi .org/10 .18203/2349-2902 . isj20173881

[16] Lund JN, Scholefield JH. Etiology and Treatment of Anal Fissure. $\mathrm{Br}$ J Surg. 1996; 83(10): 1335-44. https://doi.org/10.1002/bjs . 1800831006

[17] Abramowitz L, Sobhani I, Benifla JL, et al. Anal fissure and Thrombosed External Hemorrhoids Before And After Delivery. Dis Colon Rectum. 2002; 45: 650-655. https://doi.org/10.1007/s103 50-004-6262-5

[18] Sagap I, Remzi FH. Controversies in the Treatment of Common Anal Problems. World Journal of Gastroenterology. 2006; 12: 3146-3154 PMCid:PMC4087955 https://doi.org/10.3748/wjg.v12.i2 0.3146

[19] Cross KL, Massey EJ, Fowler AL, et al. The Management of Anal Fissure: ACPGBI position statement. Colorectal Dis. 2008; 10(3): 1-7. PMid:18954306 https : //doi .org/10.1111/j.1463-1318. 2008.01681.x

[20] Khan RM, Itrat M, Ansari AH, et al. Prevalence of Fissure-in-Ano among the Patients of Anorectal Complaints Visiting Nium Hospital. J Community Med Health Educ. 2015; 5(2): 344.

[21] Feldman M, Friedman LS, Brandt LJ. Diseases of the anorectum In: Sleisenger and Fordtran's Gastrointestinal and Liver Disease: Pathophysiology, Diagnosis, and Management. 10th ed. Philadelphia, Pa: Saunders Elsevier; 2015. 
[22] Hany S, Elgendy H, Elfeki H, et al. Does the Duration of Symptoms of Anal Fissure Impact Its Response to Conservative Treatment? A prospective cohort study. International Journal of Surgery. 2017; 44: 64-70. PMid:28629768 https://doi.org/10.1016/j.ijsu .2017 .06 .044

[23] Gupta P. Randomized Controlled Study Comparing Sitz-Bath and No-Sitz-Bath Treatments In Patients with Acute Anal Fissures. ANZ Journal of Surgery. 2006; 76(8): 718-721. PMid:16916391 https://doi.org/10.1111/j.1445-2197.2006.03838.x

[24] Jensen SL. Treatment of First Episodes of Acute Anal Fissure: Prospective Randomized Study of Lignocaine Ointment Versus Hydrocortisone Ointment or Warm Sitz Baths Plus Bran. Br Med J (Clin
Res Ed). 1986; 292(6529): 1167-1169. https://doi.org/10.1 136/bmj . 292.6529.1167

[25] Brillantino Renzi RA, Di Sarno G, D'Aniello F. Five-item score for obstructed defecation syndrome: study of validation. Surgical Innovation. 2013; 20(2): 119-125. PMid:22599920 https: //doi.org/10.1177/1553350612446354

[26] Gogna S, Goyal P, Arora B, et al. Comparative Evaluation of Efficacy of Sitz Bath Vs Lignocaine Ointment Vs Topical Glyceryl Trinitrate in Treatment of Acute Anal Fissure: A Prospective Study. IOSR Journal of Dental and Medical Sciences. 2015; 14(4): 12-14.

[27] Gupta PJ. Treatment of fissure in ano- revisited. Afr Health Sci. 2004; 4(1): 58-62. PMid: 15126193 